\title{
O cinema como cosmopoética do pensamento decolonial
}

\author{
Cinema as cosmopoetics of decolonial thinking
}

\section{CATARINA AMORIM DE \\ OLIVEIRA ANDRADE \\ UFPE \\ Professora Adjunta do}

Departamento de Letras/UFPE.

Professora colaboradora do

Programa de Pós-graduação em

Comunicação PPGCOM/UFPE

e da Pós-graduação Narrativas

Contemporâneas da Fotografia e do Audiovisual, da Universidade Católica de Pernambuco (Unicap).

Vice-líder do Grupo de Pesquisa

Laboratório de Experiência, Visualidade e Educação (LEVE). https://orcid.org/0000-0002-

2547-7118

catarina.oandrade@ufpe.br

\section{ÁLVARO RENAN JOSÉ DE BRITO ALVES \\ UFPE}

Doutorando pelo Programa de Pós-Graduação em Comunicação da UFPE, com pesquisa voltada para práticas ensaísticas no encontro entre Cinema e Educação. Pesquisador no Grupo de Pesquisa Laboratório de Experiência, Visualidade e Educação (LEVE). É formado em Cinema e Audiovisual e Mestre em Comunicação, também pela UFPE.

https://orcid.org/0000-00025259-7932

alvaro.brito@ufpe.br

\section{RESUMO}

Neste artigo pretendemos compreender se, e de que forma, o cinema pode servir a uma cosmopoética do pensamento decolonial. Para tanto, nos apoiaremos em alguns conceitos dos estudos decoloniais, que buscam atualizar a tradição crítica do pensamento latino-americano a partir da problematização do pensamento hegemônico (eurocêntrico), oferecendo novas releituras histórias e novas possibilidades de produção dos saberes. A perspectiva decolonial opera fornecendo novos horizontes para o pensamento, promovendo uma ecologia dos modos de saber e conhecimento não reconhecidos pelas epistemologias dominantes. Assim, buscamos entender a potência cosmopoética do cinema e como ele pode contribuir, dentro dos espaços de educação, como alternativa epistemológica para o pensamento decolonial.

Palavras-chave: cosmopoética; cinema; decolonialidade.

\begin{abstract}
This paper intends to understand whether - and in which way - cinema may work as cosmopoetics to decolonial thinking. In this sense, we rely on some concepts of decolonial studies, seeking to update the critical tradition of latin-american thinking by problematizing (eurocentric) hegemonical thinking, and so, offering new historical rereadings and new possibilities to knowledge production. Decolonial perspective provides new horizons to thinking by promoting an echology of ways of knowing and knowledges commonly not recognized by dominant epistemologies. Therefore, we seek to understand cinema's cosmopoetical potency and how it contributes, inside education spaces, as epistemological alternative to decolonial thinking.
\end{abstract}

Keywords: cosmopoetics; cinema; decoloniality. 


\section{INTRODUÇÃO}

O cinema nos ajuda a entender a dimensão estética da emancipação e acaba nos servindo como um princípio de igualdade.

Migliorin e Pipano

A organização do mundo contemporâneo e as formas de sua realidade são inteiramente atravessadas pela produção e circulação de imagens. No contexto de consolidação e disseminação da tecnologia digital, é lícito assumir o debate que se dá em torno da apropriação e dos usos dos objetos técnicos que formatam este universo. Longe de afastar a tecnologia e seus artefatos como máquinas de predação do capitalismo em seu estado atual, devemos nos perguntar como se faz possível emancipá-los em prol do uso comum e da atividade das formas de vida que não apenas resistem à predação, mas militam a favor de outro mundo.

Perguntamos, neste sentido, se o cinema seria uma dessas tecnologias, passíveis de serem apropriadas e emancipadas em favor de um pensamento decolonial crítico das violências e injustiças residuais do colonialismo, mas propositivo no que concerne à visada de uma transformação estrutural da sociedade. Apesar do que pensa o senso comum quando associa o cinema a produções hiperbólicas, a popularização dos artefatos proveniente da instauração do mundo digital trouxe mudanças nos hábitos, consumos e formas de uso das ferramentas de cinema. Assim sendo, verifica-se como manifestações aqui e acolá reforçam a necessidade de repensar meios e circuitos hegemônicos de produção e circulação de filmes, mas também formas de ver e perceber tais produções. O que se produz nas periferias, nas comunidades indígenas, nas escolas, e como e onde os filmes são vistos, são questões que nos induzem a admitir o cinema como um instrumento capaz de afirmar modos diferentes de vida, repensar espaços tradicionais de educação, além de inventar realidades e mundos comuns nos quais as alteridades se encontram e se encenam.

Por isso, propomos pensar o cinema como ferramenta cosmopoética de invenção do comum, vinculando-o à proposta crítica conduzida pela opção decolonial. Nossa hipótese, é que a imagem é o lugar de uma conjugação do sensível e do inteligível, e pode também ser investida de virtualidades imaginárias oriundas daqueles e daquelas que procuram existir e re-existir em meio às investidas do capital. Esta hipótese também se reporta à educação no que concerne à sua capacidade de transformar, resistindo à sua instrumentalização pela ideologia de mercado com vistas a transformar todo ser humano em capital ou recurso humano. Acreditamos que o cinema permite pensar e encenar os corpos em estado de presença, de suspensão do tempo, 
desdobrando nos sujeitos faculdades sensíveis de se reconhecer e de se reconhecerem no outro, possibilitando um verdadeiro intercâmbio cultural. O cinema investe primeiramente sobre as sensibilidades, e depois sobre a razão - fórmula que adotamos para fins didáticos - ainda que não deixe de mobilizar o pensamento, sendo assim, um veículo a que se pode atribuir a capacidade daquilo que Boaventura Souza Santos chama de corazonar.

\section{ATRAVESSAMENTOS DECOLONIAIS}

Desde o que se convencionou chamar de descobrimento das américas, um sistema-mundo (WALLERSTEIN, 1980) se instaura, com base em uma referência eurocentrada, operando a partir de uma clivagem entre países ricos e países pobres (mais tarde surgiriam os países "em desenvolvimento") e instaurando uma espécie de eterna supremacia europeia em termos político, econômico, social, racial, tecnológico, ideológico etc. Assim, não apenas as instituições modernas, mas o próprio pensamento, se constroem e se desenvolvem em torno desse ponto zero, neutro, eurocêntrico, ou seja, "o ponto do início epistemológico absoluto, mas também o do controle econômico e social sobre o mundo" (CASTRO-GÓMEZ, 2005, p.25, tradução nossa). Sobre esse ponto zero que se fundamenta na sua própria inquestionabilidade, Stam e Shohat afirmam que o eurocentrismo bifurca o mundo em "Ocidente e o resto", organizando a linguagem em hierarquias binárias que favorecem a Europa (SHOHAT e STAM, 2006, p.21). Homi Bhabha também critica a estrutura binária e busca, a partir de uma perspectiva pós-colonial, revisar as pedagogias nacionalistas que observam o mundo dentro de uma oposição binária e, ainda, resistir à busca de formas holísticas para explicações sociais (BHABHA, 2007, p.241-242). Para o autor, a perspectiva pós-colonial "força o reconhecimento das fronteiras culturais e políticas mais complexas que existem no vértice dessas esferas políticas frequentemente opostas" (BHABHA, 2007, p.241-242).

A contribuição dos estudos pós-coloniais é inegável, ela proporciona, entre outras coisas, controverter as dicotomias nas quais se baseiam todas as esferas da sociedade moderna, questionar as relações de identidade (HALL, 2003; 2003b) e de raça, repensar as formas de organização.

Os teóricos pós-coloniais iniciaram uma crítica fundamental à experiência e à lógica do colonialismo e do imperialismo em busca por restaurar, adverte Veja, a voz, a experiência, a identidade e a história do subalterno, reivindicando também a importância das localidades periféricas. (CUEVAS MARÍN, 2013, p.95, tradução nossa) 
Entretanto, alguns autores, ligados a um pensamento decolonial - que tem seu início nos anos 1990 -, como Walter Mignolo (1998), questionam a "tradução" dessas teses ligadas aos teóricos dos estudos culturais, pós-coloniais e subalternos para os estudos e as análises na América Latina. Segundo Mignolo, esses estudos não conseguem romper de forma adequada com o pensamento eurocêntrico. Diante dessa limitação, surge, no final da década de 1990, o Grupo Modernidade/Colonialidade $(M / C)$, composto por intelectuais latino-americanos, que realiza, de acordo com Luciana Ballestrin, "um movimento epistemológico fundamental para a renovação crítica e utópica das ciências sociais na América Latina no século XXI: a radicalização do argumento pós-colonial no continente por meio da noção de 'giro decolonial'" (2013, p.89).

Catherine Walsh explica que a supressão da letra "s" do termo "descolonial", marcaria uma distinção entre o momento histórico que delimita os processos de descolonização (em oposição à colonização) e o conceito de decolonialidade ligado ao Grupo M/C, que entende que a relação de colonialidade não se encerra com a descolonização.

Com esse jogo linguístico, procuro colocar em evidência que não existe um estado nulo da colonialidade, mas posturas, posicionamentos, horizontes e projetos de resistir, transgredir, intervir, in-surgir, criar e incidir. O decolonial denota, então, um caminho de luta contínuo no qual se pode identificar, visibilizar e incentivar "lugares" de exterioridade e construções alter-(n)ativas. (WALSH, 2013, p.25, tradução nossa)

A noção de giro decolonial foi desenvolvida por Nelson Maldonado Torres para situar um movimento de resistência teórico e prático, político e epistemológico, à lógica da modernidade/ colonialidade (BALLESTRIN, 2013, p.105). Esse giro aponta, então, para uma possibilidade de atualização da tradição crítica do pensamento na América Latina - e para a América Latina - e, consequentemente, a problematização das questões específicas do pós-colonialismo (enquanto momento histórico) vividas no continente. Ainda, o pensamento que emerge da noção de decolonialidade contribui para importantes releituras históricas e resgate da construção de identidade e memória individuais ou coletivas de sujeitos e povos marginalizados.

A colonialidade é identificada a partir de uma tripla dimensão: a do poder, a do saber e a do ser (BALLESTRIN, 2013, p.100). A colonialidade do poder é a que mais se evidencia, perpassando por todos os domínios da sociedade, configurando-se como uma estrutura complexa de controles, apontados por Mignolo (apud BALLESTRIN, 2013, p.100): controle da economia, da autoridade, da natureza e dos recursos naturais, do gênero e da sexualidade, da subjetividade e do conhecimento. A colonialidade do saber, problematiza a relação que a epistemologia moderna - epistemologias do Norte, para usar um termo de Boaventura de Souza Santos (2019) - estabeleceu entre as localizações geohistóricas e a produção de conhecimento. Maldonado-Torres (2007) afirma que a colonialidade do ser é "um conceito que tenta captar o modo como o feito colonial se apresenta 
na ordem da linguagem e na vivência dos sujeitos" (2007, p. 154, tradução nossa), ou seja, a colonialidade do ser age na subjetividade discursiva.

$\mathrm{Na}$ esteira de um pensamento decolonial que articule a crítica da colonialidade, Catherine Walsh (2009) explora os múltiplos sentidos que o termo interculturalidade vem ganhando desde os anos 1990, especialmente no que diz respeito ao âmbito educacional, apontando para uma interculturalidade crítica, concebida como um projeto político de descolonização, transformação e criação (WALSH, 2009, p.2). O debate sobre interculturalidade se torna fundamental para (re) pensar a construção coletiva do conhecimento (se e como ela é possível), e sua reconstrução a partir de referenciais outros. Walsh se apoia no pensamento do filósofo peruano, Fidel Tubino (2005) para quem é preciso pensar uma interculturalidade que questione as regras do jogo e que não seja compatível com a lógica do modelo neoliberal. Distingue-se, assim, três perspectivas para o uso do termo interculturalidade no contemporâneo: relacional, funcional e crítica.

A interculturalidade relacional diz respeito ao contato e intercâmbio entre culturas, pessoas, práticas, saberes, valores, tradições, podendo se dar em condições de igualdade ou desigualdade (WALSH, 2009, p.3). Essa perspectiva trata apenas do contato e da relação e não coloca em questão o sistema de dominação, as contradições e os conflitos. A interculturalidade funcional, como o nome já diz, é funcional ao sistema, assumindo seu discurso. Ou seja, a interculturalidade funcional não apenas não atua nas assimetrias e desigualdades, como serve de suporte mesmo para sua manutenção. Sobre como se produz a interculturalidade funcional, Walsh aponta que "a onda das reformas educacionais ${ }^{[1]}$ constitucionais dos anos 90 - que reconhecem o caráter multiétnico e plurilinguístico dos países e que introduzem políticas específicas para os indígenas e os afrodescendentes - são parte desta lógica multiculturalista e funcional". (WALSH, 2009, p.3, tradução nossa). Por fim, a interculturalidade crítica, ao colocar em questão a manutenção das estruturas de desigualdade, é entendida de forma processual, como uma ferramenta, um projeto que se constrói para e com as pessoas, jamais imposta.

Interessa, portanto, pensar a interculturalidade crítica como processo, especialmente dentro do campo pedagógico e educacional, uma vez que "seu projeto não é simplesmente reconhecer, tolerar ou incorporar o diferente dentro da matriz e estruturas estabelecidas", mas "re-conceituar e re-fundar estruturas sociais, epistêmicas e de existências, que colocam em cena e em relação equitativa lógicas, práticas e modos culturais diversos de pensar, atuar e viver" (WALSH, 2009, p.4, tradução nossa). Ela deve fazer parte de um programa social, político, epistemológico, questionando não apenas o discurso dominante, mas assumindo um discurso próprio capaz de romper com as estruturas de dominação.

Enquanto no interculturalismo funcional se busca promover o diálogo e a tolerância sem tocar as causas da assimetria social e cultural hoje vigentes, no interculturalismo crítico se busca suprimi-las por métodos políticos, não 
violentos. A assimetria social e a discriminação cultural tornam viável o diálogo intercultural autêntico. (TUBINO, 2005, p.2, tradução nossa)

As trocas interculturais pressupõem presença. Segundo Boaventura de Souza Santos, "a presença é a 'coisidade' ou a materialidade sobre a qual se constroem sentidos" (2019, p.156). Também no cinema a presença é um pressuposto, ela é o leitmotiv de sua realização. Os corpos, sejam eles humanos ou não-humanos, no espaço fílmico, e os corpos, humanos, dos espectadores, em relação ao filme, estão todos em presença ou, ainda, em copresença. Nesse sentido, o cinema se constrói como um campo potencial de "aquecimento da razão", que Souza Santos chamará de corazonar. Para o autor, "corazonar é uma forma amplificada de sercom, pois faz crescer a reciprocidade e a comunhão", significa "assumir uma responsabilidade pessoal acrescida de entender e mudar mundo" (2019, p.154-155). O cinema, então, pode ser entendido como uma espécie de forma sensível, manifesta, da noção de corazonar, uma vez que opera nesse lugar de "aquecimento da razão", estabelecendo uma relação permanente entre a razão e a emoção.

\section{COMUNIDADES DE CINEMA E COSMOTECNOLOGIA}

No Brasil, a experiência desenvolvida em continuidade pelo projeto Vídeo nas Aldeias ${ }^{[2]}$ consolidou nas comunidades indígenas a prática de cinema, retomada e apropriada de formas diferentes. Quando um povo se apropria de uma ferramenta e o retira de suas dinâmicas naturalizadas, o aparato tecnológico recebe novos sentidos, mas torna-se também parte processual da dinâmica de vida desse povo. Também podemos mencionar o projeto Inventar com a diferença - cinema e direitos humanos, idealizado pelo Departamento de Cinema da UFF em parceria com a Secretaria de Direitos Humanos. O site do Inventar... oferece um mapa regional com os projetos e intervenções parceiros executados por todo o país durante o ano de 2017. A leitura das sinopses de cada projeto conduz, em sua quase totalidade, à temática dos direitos humanos ${ }^{[3]}$, da constituição e reconhecimento de identidades e preservação da memória ${ }^{[4]}$, mas também da comunicação e tradução das alteridades nos projetos executados em zonas de fronteiras e territórios indígenas ${ }^{[5]}$.

Quando observamos de perto, tais experiências apontam para um desejo de reconhecimento social que tem como horizonte a inserção na experiência da construção de um mundo comum e do exercício de uma democracia mais inclusiva. Todos os projetos parceiros do Inventar... se 
ajustam às premissas da discussão que Jacques Rancière $(2009,2012)$ traz no bojo de suas reflexões sobre a política como partilha do comum e a constituição de uma comunidade dos iguais tendo como princípio uma igualdade das diferenças. Gostaríamos de enfatizar as premissas deste debate através do conceito de cosmopoética, já que se trata de produzir o mundo como mundo comum, e verificar a possibilidade de uma articulação deste pensamento com a opção decolonial.

Emprestamos o conceito de cosmopoética de Marcelo Ribeiro (2016, p.4), que a define como o conjunto de "formas de invenção (poiesis) do mundo como mundo comum (cosmos)" - significando a constituição de um mundo objetivado não apenas na ordem de suas leis e de sua constituição jurídico-política, mas principalmente como comum investido por certos regimes de inteligibilidade, de visibilidade e de sensibilidade. Por isso, segundo Ribeiro, uma cosmopoética não se dá sem uma cosmopolítica, que constitui os "conjuntos de discursos e de práticas associados à configuração e ao recorte do mundo (cosmos) como comunidade política (polis)" (2016, p.4). Acreditamos que o cinema é uma importante ferramenta e um meio fundamental na produção de realidades comuns, principalmente quando o tomamos como espaço ou reserva de experimentação e imaginação do mundo, em oposição ao mundo dado como feito, concluído e acabado, que a televisão e os telejornalismos apresentam como fato, bem como ao mundo liquefeito, graças à circulação estonteante de imagens de choque imediato, geralmente descontextualizadas, insituáveis ou esvaziadas de sentido, nos meios digitais.

Por isso, dizemos que o cinema constitui uma "cosmotecnologia" - compreendida de maneira radical na esteira das definições que certa linha de pensamento da antropologia atribui ao xamanismo, sob as rubricas de "técnicas de êxtase", "tecnologias de encantamento" e "tecnomagias"[6] - que aqui podem ser resumidas como o conjunto de técnicas, instrumentos e práticas que constituem a tecnologia e o modus operandi das formas de conhecimento e experimentação do mundo comum - investido pelas virtualidades da memória, do imaginário bem como das narrativas mitopoéticas.

Se por cosmopoética se entende a invenção de um comum, o cinema como ferramenta cosmotecnológica vem como intervenção no mundo, um investimento redistributivo deste comum, sempre capaz de instaurar comunidades dissensuais ao ser apropriado por povos não hegemônicos, grupos minoritários ou sujeitos periféricos. Por comunidade, entende-se as novas formas de viver junto, em meio a um mundo cujas forças sociais - as maneiras, formas e estruturas que organizam a sociedade - cada vez mais desagregram, privatizam ou tornam exclusivos certos espaços do comum. Partimos das reflexões de César Guimarães (2015) ao elaborar sobre as comunidades de cinema. O autor apoia-se na chave conceitual de Jean-Luc Nancy e Jacques Rancière, para se pensar as diferenças propositivas entre comunidade e comum, a primeira refere-se aos laços invisíveis que se estabelecem e criam mundos tornados visíveis, dizíveis e partilháveis que constituem o último. Assim, fala-se 
nas possibilidades de invenção do comum que laços provisórios instauram à medida que diferentes sujeitos acedem ao lugar de sua partilha.

Para César Guimarães (2015), por comunidades de cinema, entende-se os "diferentes processos de constituição da visibilidade cinematográfica" por demandas estéticas que, eventualmente, condicionam a aparição de um novo comum à ruptura dos regimes naturalizados do sensível. ${ }^{[7]}$ Neste sentido, ele chama de "comunidade de cinema" aquela que advém das práticas cinematográficas quando investidas por desejos de transformação. O cinema, então, instaura o dissenso nas malhas do visível, abrindo a brecha para a constituição de uma comunidade ainda por vir. Guimarães fala, partindo de Jean-Luc Nancy, da instituição de uma comunidade política como "laço social por dar" ao se debruçar sobre o documentário brasileiro contemporâneo, interessado nos últimos anos em filmar "não só o rosto, mas também os gestos, os corpos e os discursos de todos aqueles que, incluídos por exclusão na cena política", conforme escreve, retomando a expressão de Rancière, "alcançam uma posição que lhes permite tornar visível o que não era visto e sustentar uma fala em contraposição a uma condição que os reduzia a animais barulhentos" (2015, p.46).

De outro modo, Mircea Eliade (1998) chama de "técnicas do êxtase" o conjunto de operações realizadas pelos xamãs para entrar em contato controlado com o tempo mítico. Nesse conjunto, encontram-se os mitos e rituais, a que o autor chama de "tecnologias do encantamento", operações técnicas passíveis de serem apropriadas pelos "não-xamãs" capazes de emular o tempo mítico para eles. Segundo Sullivan, a "capacidade de saber por imitação ou representação simbólica constitui a essência da tecnologia e serve, nas formas de arte, música, uso de ferramentas e ação ritual, como fundamento da criatividade e da cultura humana" (SULLIVAN, 1988, p.237). É a isso que chamamos tecnologias míticas. Sullivan (1988, p. 401) aprofunda a noção de "tecnologia xamânica" definindo tecnologia como "conhecimento íntimo e sistemático" (1988, p.404) e fazendo uma associação do saber e de suas tecnologias à dimensão mítica. Não por acaso, o cinema, fábrica de sonhos, foi também associado aos mitos e medos formadores das sociedades ocidentais, e mais além, como se verifica na apropriação de suas ferramentas por povos não europeus, constituidor de cosmopoéticas periféricas, contra-hegemônicas e decoloniais.

Sullivan (1988, p.419) diz também que o "corpo do xamã é parte de sua tecnologia", enquanto Viveiros de Castro (1996, p.131) ${ }^{[8]}$ afirma que o corpo é "lugar da perspectiva diferenciante". Ora, um corpo com uma câmera é a constituição analógica desta dupla definição, posto que a câmera é o que conjuga o movimento do mundo com as suas virtualidades intensivas. Viveiros de Castro, ao desenvolver essa noção do corpo como lugar da perspectiva diferenciante, constata que o corpo é passível de metamorfose através das conexões que estabelece com objetos, roupas e próteses, bem como instrumentos. Ele argumenta que, muitas vezes, entre os povos ameríndios, os rituais de socialização servem precisamente para produzir a humanidade de um 
corpo ainda não-humano, da mesma forma que o corpo xamânico precisa ser produzido pelo distanciamento dos traços que o caracterizam como tal. É neste sentido que chamamos atenção para a apropriação da ferramenta cinema por povos indígenas.

Nesse sentido, André Brasil (2016) discorre sobre certa cinematografia indígena que funda sua visibilidade em um incessante comércio com o invisível sob a forma de uma tradução xamânica. ${ }^{[9]}$ Um mapeamento breve de pesquisas acadêmicas torna possível visualizar a amplitude e complexidade das cinematografias indígenas no Brasil. Pesquisadores como Dominique Gallois (1991; 1995), Ruben Caiexeta de Queiroz (2008, 2013, 2018), Renata Otto Diniz (2018), André Brasil (2012, 2013, 2016), Amarante Cesar (2015), Bernard Belisário (2016) redistribuem as perspectivas sobre elas, manejando diferentes questões e os objetos de estudo a partir de variadas abordagens, que assinalam como os povos originários deixam de ser "objetos" fílmicos para aceder a sujeitos do fazer cinematográfico, donos de um ponto de vista que reverte a forma clássica antropológica ao fazer da imagem e da cena o abrigo de suas auto-mise-en-scèna. Marcos Aurélio Felipe aponta como as temáticas e abordagens dessas cinematografias nos provocam e nos instigam como pesquisadores a pensar "os desdobramentos dos dispositivos espectatoriais na formação de comunidades de cinema e as especificidades do olhar nativo" (FELIPE, 2019, p.4). Como sugere Felipe, não é só a visão clássica do índio que é posta em questão, mas o próprio campo cinematográfico é perturbado pelas dimensões cênicas, dramatúrgicas e criativas do cinema indígena, quando pensamos suas diferentes formas de (re)encenação, filme-processo e auto-etnografias; bem como o fazer documentário se transforma através do investimento cosmológico nativo.

Paralelamente, a formação das cinematografias indígenas a partir da atuação do VNA aponta para uma reinscrição no seio das comunidades indígenas de uma prática que transcende suas circunstâncias culturais (AUFDERHEIDE, 2011, p.185). O uso da tecnoferramenta cinematográfica é assim apropriada por esses povos como forma de se afirmar e comunicar em um mundo que sempre condicionou sua visibilidade as formas e valores de certa civilização. Assim, as cinematografias indígenas surgem como gesto político de instauração de um regime de visibilidade e sensibilidade até então ignorado - o que torna possível autores como Ruben Caixeta de Queiroz e Renata Otto Diniz (2018) falarem de uma "cosmocinepolítica" indígena. No seio dessas cinematografias, constam nomes como Divino Tserewahú entre os xavantes, Isael e Suely Maxacali entre os tikm'n, que fazem da prática cinematográfica um processo ritualístico - filmesrituais investidos por suas cosmologias e seus desejos de mundo ${ }^{[10]}$.

Portanto, entendemos o cinema como cosmopoética do pensamento decolonial no seu lugar da experiência e do comum, configurando-se como um lugar de re-existência. Adolfo Albán chama de re-existência os dispositivos criados e desenvolvidos para nos inventarmos, em comunidade, cotidianamente, reinventando as formas de dispor da vida e dos poderes (ALBÁN, 2013, p.455), 
no intuito de confrontar as imposições imperialistas dentro dessa realidade estabelecida por um projeto hegemônico e homogeneizador. Uma realidade em que, nos alerta Jonathan Crary, "o ataque a valores de coletividade e cooperação é articulado por meio da noção de que a liberdade é estar livre de qualquer dependência em relação aos outros, enquanto na verdade vivemos uma sujeição mais completa ao funcionamento 'livre' dos mercados" (2016, p.95). A re-existência perpassa, então, um deslocamento de paradigma capaz de nos desalienar de certa condição a qual as forças do mercado e do Estado nos colocaram - condição subalterna de sujeitos alijados dos processos deliberativos pelos quais o comum é decidido e partilhado. Daí que re-existir significaria devolver nossa capacidade de dispor da vida e de nossos devires, satisfazendo um sentimento de resistência contra as forças que os alienam.

Perguntamos, por isso, se o cinema não traz a possibilidade de uma invenção do comum sob um ponto de vista pedagógico e decolonial, já que opera no âmbito sensível das maneiras de ser e de fazer, das formas de visibilidade que designam e são designados pelos atores sociais. Se o pensamento decolonial reivindica uma mudança qualitativa nos modos de vida, através de uma intervenção radical nos regimes de saber, de ver e sentir, parece-nos que sua política assemelha-se à definição de Rancière: político é "quando aqueles que não tem tempo tomam esse tempo necessário para se colocar como habitantes de um espaço comum e para demonstrar que [...] suas bocas emitem uma palavra que enuncia algo do comum e não apenas uma voz que sinaliza dor" (2010, p.21). Em resumo - parafraseamos - político é a tomada de tempo, a enunciação de uma voz e a aparição na visibilidade dos sujeitos excluídos que assim podem afirmar sua existência como parte sensível da arena social - redistribuindo os lugares, desestabilizando as identidades, dando forma ao barulho por meio da palavra e visibilidade àqueles que antes eram invisibilizados.

\section{CINEMA, EXPERIÊNCIA E IMAGINAÇÃO}

Alain Badiou entende o cinema como experimentação filosófica tendo em vista que uma situação filosófica é "um encontro de termos estranhos uns aos outros", "a elucidação de uma escolha", "uma relação paradoxal" (2015, p.31-36). Para o autor, então,

O paradoxo do cinema pode ser definido de duas maneiras: a primeira, mais filosófica, é dizer que ele constitui uma relação inteiramente singular entre o artifício total e a realidade total. De fato, o cinema é a possibilidade de uma reprodução da realidade e, ao mesmo tempo, o lado inteiramente artificial dessa reprodução. Em outras palavras, o cinema é um paradoxo que gira em torno do "ser" e do "parecer". (BADIOU, 2015, p.36) 
Nesse sentido, podemos dizer que o cinema se configura como um espaço de uma outra realidade possível, de uma abertura para outras releituras e interpretações do mundo. No cinema, o que se passa é um deslocamento qualitativo entre o mundo e a imagem do mundo, operada por uma mediação espectatorial. A tensão entre o "ser" e o "parecer" induz uma tomada ética de posição do olhar, desvinculada, contudo, dos moralismos de uma racionalidade que privilegia o ser em detrimento do "não-ser". É neste intervalo ínfimo entre o ser e o parecer que se instala o espaço de imaginação não menos real quanto a realidade que projetamos sobre o próprio mundo.

O cinema expõe a tensão originária, o paradoxo constitutivo da formação das ordens societais - a artificialidade de suas instituições, de seus ritos e crenças, das hierarquias e privilégios de classes -, bem como encena a arbitrariedade das posturas e dos gestos que designam o regime de visibilidade que investem essas mesmas ordens. Os filmes põem em cena o cadinho das relações sociais e humanas e, ao fazê-lo, instituem um espaço irisado da experiência complicada no entrelaçamento de uma tríplice dimensão: da ordem do inteligível, do sensível e, não menos importante, do imaginativo. Assim a experiência, sempre complexa, apresenta-se em tonalidades múltiplas no sensível e na percepção - sendo mais ou menos intensa para uns do que para outros, mas acionando diferentes frequências nas sensibilidades germinantes.

Cezar Migliorin e Isaac Pipano (2019, p.97) nos lembram que "o cinema, assim como a educação, funciona devolvendo algo do sujeito ao mundo, inventando um receptor para essa devolução. Uma devolução que não da coisa em si, mas da coisa atravessada por uma mediação estético-política". Ao inventar este espectador, o cinema inventa as condições de mediação pelas quais o mundo é reinventado em imagem - imagem como forma inteligível e sensível, mas, igualmente como reserva de imaginação, imagem em ação. Assim, pode-se dizer que o cinema faz experiência por meio de uma tomada e uma devolução estético-política do mundo, transfigurando-o e perturbando, por vezes, as naturalizações do olhar, por um lado, e, por outro, transformando os regimes normativos das maneiras de ver, perceber e sentir.

Outra forma de conhecer, o cinema caracteriza-se por sua extrema visibilidade, mas também pela vibração luminosa que Ihe confere a irisação cromática dos afetos e emoções que as imagens veiculam. Seria preciso então reabilitar, nos processos educativos, de um lado o sentido da experiência e de outro o da imaginação. Assim, associando-se os dois, dizemos com Agamben que

\footnotetext{
Nada pode dar ideia da dimensão da mudança ocorrida no significado da experiência como a reviravolta que ela produz no estatuto da imaginação. Dado que a imaginação, hoje, eliminada do conhecimento como sendo 'irreal', era para a antiguidade o médium por excelência do conhecimento. [...] Longe de ser algo irreal, o mundus imaginabilis tem a sua plena realidade entre o mundus sensibilis e o mundus intellegibilis, e é, aliás, a condição de sua comunicação, ou seja, do conhecimento. (AGAMBEN, 2005, p.33)
} 
É esse sentido da imaginação, sua capacidade mediadora como condição da comunicação e do conhecimento que Adriana Fresquet afirma como elementar na experiência da educação por meio do cinema (2017, p.29). O cinema oferece a possibilidade de experimentar o mundo a partir de seus próprios elementos - o real como matéria prima de uma linguagem - mas não menos pelos investimentos da imaginação. Não por acaso, Pasolini $(1982$, p138) dizia do cinema que este era a escrita do real, porque o real, ainda que confinasse sua aparição à condição criptográfica tal qual os hieróglifos, constituía a sua matéria expressiva por excelência, e era por sua capacidade de conjugar uma "qualidade onírica" à aparição dos objetos que o cinema não podia esgotar os esforços de se fazer "cinema de poesia". Essa escrita do real estaria sempre à espera de uma decodificação, de um jogo de tradução. Mas se há decodificação possível, é apenas por meio de uma relação especular, sensível com os meios expressivos do próprio cinema. É nessa esteira que Migliorin se situa quando afirma sobre cinema que, se "por um lado, ele é mundo, por outro ele é alteração" imaginativa (MIGLIORIN, 2010, p.106).

A experiência como fundação de saber é pensada por Larrosa (2002) em termos de uma interrupção no fluxo da realidade. Se, por um lado, a imaginação inerva a experiência, por outro, a experiência se dá na carne do real. Larrosa propõe um saber da experiência como alternativa à pedagogia entendida seja como ciência aplicada, seja como práxis crítica. O que nos interessa é a sua definição de experiência como aquilo "que nos passa" que se funda na duração do tempo e na disponibilidade exercitada nos sujeitos para ver, ouvir, perceber, sentir e conhecer as coisas (2002, p.21-24). Larrosa retoma também o sentido diaspórico presente na etimologia da palavra: ex-pereor supõe a aventura da viagem, o deslocamento para fora das fronteiras, bem como a travessia e o exílio (2002, p.25). Interessa aqui perceber o cinema como um produtor de experiência que desloca a consciência de ser e estar, a ideia de sujeito, em direção à alteridade e ao desconhecido. Por outro lado, o saber fundado na experiência é também um saber dos sentidos, aquém ou além da cognição do mundo.

Se é verdade que o cinema dá uma visibilidade ao mundo de tal forma que é capaz de "alteráIo", seria possível compreendê-lo, então, em uma perspectiva pedagógica, como ferramenta cosmopoética que visa uma transformação, uma reinvenção do mundo como comum, pois, à medida que transforma nossa percepção sobre o mundo, o cinema é capaz de fazer perceber as estruturas de poder no interior das produções sociais e culturais da civilização. Se o pensamento decolonial é uma questão de atitude, de postura frente ao mundo, o cinema pode ser o meio pelo qual esta postura, esta atitude, são encenadas - e transfiguradas. O cinema é o lugar, também, do comum, o nome que se dá ao espaço da partilha e distribuição das posições e dos liames sociais, ao mesmo tempo da comunicação e aproximação - entre diferentes sujeitos, entre humanos e não humanos - e da distância e separação - que não deixam de preservá-lo como 
lugar do outro e do heterogêneo, da dissidência e do dissenso. Comum, como resume Rodrigo Silva, "que seja espaço de inclusão ou de abertura ao 'desconhecido comum', um convite à conjunção sem identificação, à existência dada na exterioridade da relação e não na interioridade de uma identificação ou uma 'comunhão'"' (2011, p.24). Comum como coexistência das diferenças e co-extensão das distâncias que conectam e separam. O jogo possível da democracia, portanto, encontra-se indissociável da invenção de um comum.

\section{CONSIDERAÇÕES FINAIS}

A opção decolonial pressupõe uma forma de escovar a história da cultura ocidental a contrapelo, um gesto de resgate nas dobras da história das ideias, dos saberes e das formas de vidas silenciadas pelo processo colonial. O cinema, por muito tempo, foi associado ao conjunto dos instrumentos técnico-pedagógicos de integração dos povos originários e de alienação das populações marginalizadas. A democratização de suas ferramentas permitiu uma reorientação de sentido. Para nós, então, o cinema vem reposicionar a questão de Marie-José Mondzain (2002): "podem as imagens matar?" cuja formulação emprestamos de Amaranta César (2013): "podem as imagens salvar?". Significa dizer que a imagem é tomada no centro do debate estético e político, que decide pela vida cultural e social dos povos e grupos minoritários, no âmbito de suas lutas e reivindicações. Ao reorientar o debate sobre as imagens numa perspectiva decolonial, perguntamo-nos se o cinema - e que cinema - é capaz de realizar reivindicações políticoexistenciais que esses povos e grupos lançam ao mundo.

Se a imagem efetivamente comporta as virtualidades do desejo e do imaginário, se dela se pode dizer que opera sobre a realidade reinvestindo-a de camadas de sentido, de afeto e imaginação, encenando concepções e modos de vida ameaçados, pode-se dizer que, sendo produtor de imagens, o cinema é, com direito, uma tecnologia de encantamento. O cinema como uma cosmotecnologia encantatória faz do mundo real a matéria prima, a arquitetura dos desejos e imaginários, de onde extrai suas próprias potências. Das imagens dizemos, então, que são a contraparte do real, sua parte maldita, não-dita - mais propriamente, não-vista ou mal vista. Mas assim o é, porque são elas mesmas o espaço de transfiguração do real, de transfiguração das lutas perdidas ou ainda não realizadas, dos desejos de transformação de mundo, das modalidades de re-existência plástica das vidas marginalizadas. 
Perguntamo-nos que sorte de cinema realiza ou estaria apto a encenar as concepções subjacentes às práticas de re-existência. Também, buscamos compreender em que o advento do cinema nas práticas cotidianas de determinados grupos pode contribuir para pensar horizontes educacionais, político-existenciais e socioculturais baseados em uma outra economia das ideias e das imagens não restritas aos dualismos do regime de pensamento ocidental[11]. Por fim, acreditamos que é a partir de sua potência cosmopoética que se instaura e se restaura um cinema possível ao pensamento decolonial e às questões urgentes que ele envolve em nossa sociedade.

\section{REFERÊNCIAS}

ALBÁN, Adolfo. Pedagogías de la re-existencia, artistas indígenas y afrocolombianos. In: WALSH, Catherine. Pedagogías decoloniales: Prácticas insurgentes de resistir, (re)existir y (re)vivir. Tomo 1. Quito: Abya Yala, 2013.

AUFDERHEIDE, Pat. Vendo o mundo do outro, você olha para o seu: a evolução do projeto Vídeo nas Aldeias. In: ARAÚJO, Ana Carvalho Ziller (org.). Video nas Aldeias 25 anos 1986-2011). Olinda, Vídeo nas Aldeias, 2011. P.180-186.

BALLESTRIN, Luciana. América Latina e o giro decolonial. Revista Brasileira de Ciência Política, no11. Brasília, pp. 89-117, maio - agosto de 2013.

BELISÁRIO, Bernard. Ressonâncias entre cinema, cantos e corpos no filme As Hiper-mulheres. In: Galáxias, São Paulo, n.32, p.35-79, ago. 2016.

BRASIL, André. Bicicletas de Nhanderu: lascas do extracampo. In: Devires - cinema e bumanidades, Belo Horizonte, v.9, n.1, p.98-117, jan./jun. 2012.

Mise-en-abyme da cultura: a exposição do “antecampo" em Pi’õnhitsi e Mokoi Tekoá Petei Jeguatá. In: Significaşão, São Paulo, v.40, n.40, p.245-265, jul./dez. 2013.

Ver por meio do invisível: o cinema como tradução xamânica. In: Novos estudos, São Paulo, v.35, n.3, p.125146, nov. 2016.

Rumo a Terra do Povo do Raio: retomada das imagens, retomada pelas imagens em Martírio e Ava Yvy Vera. In: ENCONTRO ANUAL DA COMPÓS, 27, 2018, Belo Horizonte, PUC-MG, 2018.

CAIXETA DE QUEIROZ, Ruben. Cineastas indígenas e pensamento selvagem. In: Devires - cinema e bumanidades, Belo Horizonte, v. 5, n. 2, p. 98-125, 2008. 
Política, estética y ética no projeto Vídeo nas Aldeias. In: Cuadernos Inter-c-a-mbios, Costa Rica, v. 10, n. 12, p. 37-47, 2013.

; DINIZ, Renata Otto. Cosmocinepolítica Tikm'n-Maxakali: ensaio sobre a invenção de uma cultura e de um cinema indígena. In: Gis, São Paulo, v. 3, n. 1, p. 63- 105, jul. 2018.

CESAR, Amaranta. Sobreviver com as imagens: o documentário, a vida e os modos de vida em risco. In Devires v.10, n.2, p.1223, Belo Horizonte, 2013.

CRARY, Jonathan. 24/7: Capitalismo tardio e os fins do sono. São Paulo: Ubu Editora, 2016.

CUEVAS MARÍN, Pilar. Memoria Colectiva: hacia un proyecto decolonial. In: WALSH, Catherine. Pedagogías decoloniales: Prácticas insurgentes de resistir, (re)existir y (re)vivir. Tomo 1. Quito: Abya Yala, 2013.

ELIADE, Mircea. O Xamanismo e as técnicas arcaicas do êxtase. São Paulo: Martins Fontes, 1998.

FERREIRA, Pedro Peixoto. Os Xamãs e as Máquinas: sobre algumas técnicas contemporâneas do êxtase. In Tecnomagia. BELISÁRIO, Adriano (org.) Rio de Janeiro: Imotirõ, 2014.

MALDONADO-TORRES, Nelson. Sobre la colonialidad del ser: Contribuciones al desarrollo de un concepto. In CastroGómez; R. Grosfoguel (Comps.), El giro decolonial. Reflexiones para una diversidad epistémica más allá del capitalismo global. Bogotá: Universidad Javeriana-Instituto Pensar, Universidad Central-IESCO. Siglo del Hombre Editores. 2007.

MIGLIORIN, Cezar. Cinema e escola sob o risco da democracia. Dossiê: Cinema e educação: uma relação sob a hipótese de alteridade. Revista Contemporânea de Educação, Rio de Janeiro, v.5, n.9, p.104-110, jan./jul. 2010.

MIGLIORIN, Cezar; PIPANO, Isaac. Cinema de Brincar. Belo Horizonte: Relicário, 2019.

MIGNOLO, Walter (1998). Postoccidentalismo: el argumento desde América Latina, em CASTRO-GÓMEZ, Santiago \& MENDIETA, Eduardo (coords.). Teorías sin disciplina: latinoamericanismo, poscolonialidad y globalización en debate. México: Miguel Ángel Porrúa, 1998.

MONDZAIN, Marie-José. L'image, peut-elle tuer? Paris: Bayard Éditions, 2002.

PASOLINI, Pier Paolo. Empirismo hereje. Lisboa: Assirio \& Alvim, 1982.

RIBEIRO, Marcelo Rodrigues Souza. Cosmopoéticas da descoloniz̧ação e do comum: inversão do olhar, retorno às origens e formas de relação com a terra nos cinemas africanos. In Revista Brasileira de Estudos de Cinema e Audiovisual, Rebeca 10, v. 5, n. 2, jul-dez. 2016, p. 1-26.

SULIVAN, Lawrence E. Icanchu's Drum: An Orientation to Meaning in South American Religions. New York: Macmillan, 1988. 
TUBINO, Fidel. La interculturalidad crítica como proyecto ético-político. In: Encuentro continental de educadores agustinos. Lima, 24-28 de enero de 2005. Disponível em: http://oala.villanova.edu/congresos/educación/limaponen-02.html.

VIVEIROS DE CASTRO, Eduardo. Os Pronomes Cosmológicos e o Perspectivismo Ameríndio. In Mana vol.2, n.2, p.115-44.

[1] No Brasil, essa política multicultural recebe seu tratamento sob a Lei das Diretrizes e Bases da Educação Nacional (LDB), sancionada em 1996, e incrementada com a Lei 10.639, em 2003. Ambas procuram trazer a incumbência de promover a valorização de conhecimentos sobre a história africana e afrodiaspórica, tornando obrigatório, por exemplo, o ensino da história e da cultura africana e afro-brasileira no currículo escolar. Ainda que sua implementação tenha trazido transformações consideráveis, seus efeitos desejados foram neutralizados por certa tendência estacionária do sistema educacional brasileiro. Mesmo a mudança no conteúdo curricular acaba sendo minorada por essa lógica multiculturalista, funcional, no fundo estéril quanto a garantir uma verdadeira transformação social por meio do intercâmbio cultural.

[2] Ver, por exemplo, NUNES, Macedo Karliane. (R)existir com imagens: considerações sobre a produção audiovisual indigena no Brasil. In Brasiliana - Journal for Brazilian Studies. V.5, n.1, 2016.

[3] Dos quais se destacam os projetos voltados para escolas de periferia e centros socioeducativos, situados em grande parte em áreas urbanas, tais como "Cinema na Escola, Construindo Espaços de Cidadania”, nas escolas públicas da Grande Florianópolis; "Cartas ao Mundão”, que levou oficinas a seis Unidades Socioeducativas na Região Metropolitana de Recife (PE), entre muitos outros.

[4] Como no caso do projeto "Juventude do Campo: Cinema, Identidade e Representações", em assentamentos de Corumbá, Cidrolândia e Ponta Porã (MG) com o objetivo de dar visibilidade social aos jovens do campo; do "Afroeducom”, em Curitiba (PR), no qual se tentou promover uma reflexão sobre as expressões de racismo no cotidiano de jovens negros; do "Guardiães da Memória", que atuou em escolas indígenas junto ao Povo Guarani-Mbya no Estado do Rio de Janeiro, entre outros.

[5] É o caso do "Inventar Cinema de Fronteira", em Boa Vista (RR), na Comunidade Indígena de Canauaim; do "Igualdades na Diferença: Singularidades entre Estudantes do Assentamento Rural de Rio Pardo e a Etnia Waimiri-Atroari”, em Presidente Figueiredo (AM).

[6] Sobre a definição de xamanismo como "técnicas de êxtase" e "tecnologia de encantamento", ver Eliade, Mircea (1998), Sullivan (1988) e a coletânea Tecnomagia (2014), organizado por Adriano Belisário. 
[7] Essa ruptura se dá a cada vez que surgem novas demandas e vontades por formas de criar e narrar. No cinema, ela se dá como transfiguração dos signos, das formas e dos processos do próprio fazer cinematográfico, que perturbam a cena constituída do comum e os regimes de sensibilidade pelos meios expressivos que constituem um filme. Pensamos também que, para além dos filmes que operam novas partilhas do sensível e do comum, os encontros e circuitos criados pelos modos de ver junto, as vizinhanças de olhares heterogêneos que o cinema instaura, suas formas de organização, posição e disposição dos corpos e das subjetividades próprias à instituição cinematográfica, também condicionam o estabelecimento de comunidades de cinema.

[8] Interessante, também, seria verificar, através de revisão, o que há de "diferencial” ou "diferenciante" na apropriação do vídeo pelos Kaiapós, como encontra-se registrado no Terence Turner. TURNER, Terence. Imagens desafiantes: a apropriação Kaiapó do vídeo. In Revista de Antropologia, vol. 36, p.81-121, 1993.

[9] Interessante conceito proposto por Brasil (2016) para pensar, na esteira da "crítica xamânica da economia política da natureza" do antropólogo francês Bruce Albert, uma “crítica xamânica da economia política da imagem” nas cinematografias indígenas a partir de uma reelaboração do estatuto da imagem a partir do xamanismo yanomami.

[10] Para citar apenas alguns trabalhos exemplares de como se dá este investimento cosmológico, o filme Pi’õnhitsi, Mulheres Xavante sem nome (2009), de Divino Tserewahú e co-direção de Thiago Campos Tôrres, e os curtas Yãmîy (2012) e Xupapoynãg (2013), de Isael Maxakali com assistência de Suely, nos quais o ritual constitui a cena fundamental a partir da qual seus mundos são narrados e dados a ver. Como se pode ver no filme homônimo, s yãmîy são “espíritos” mutantes do panteão maxakali que, emulados em ritual, fazem multiplicar os jogos e as micro-narrativas com que os tikm'n contam suas histórias; já o xupapoynãg é o yãmîy da lontra, animal sagrado que não pode ser abatido; no seu ritual, tal como é mostrado neste segundo curta, as mulheres são convocadas a expulsar seus espíritos, que vão à aldeia incumbidos de cobrar vingança. Em Pi’õnhitsi, a festa de iniciação das mulheres, rito que já há muito tempo não se encontra em nenhuma outra aldeia, é a cena que Divino busca filmar ao longo de anos, sem sucesso, por diferentes motivos e acidentes que atrapalham as filmagens e a própria festa; o ritual, por outro lado, gera expectativas e temores entre os xavantes.

[11] Se é possível um cinema capaz de articular o invisível no visível, efetuando o que André Brasil chamou de uma "crítica da economia política da imagem” a partir de uma tradução xamânica cinematográfica, não seria possível também uma cinematografia empenhada em encenar modos de vida baseados no buen vivir (dos povos quíchua), efetuando assim uma oyko-nomy (economia) voltada para a administração da escassez, ao invés da busca pela acumulação - economia esta que Mignolo (2008) sugere chamar de ayllu-nomy quando propõe a desobediência epistemológica pela opção decolonial? Ou seja, de que modo um certo cinema e suas práticas podem se articular a um pensamento voltado à integração das dimensões econômica, social, política e educacional da vida comunal dos diversos povos não ocidentalizados ou marginalizados? Oportuno mencionar, igualmente, as modalidades de ocupação e de existência que se (re)afirmam em seu território originário dado a ver pelas cinematografias indígenas, criando práticas de insurgência e re-existência, que André Brasil (2020) enxerga, por exemplo, num filme sobre os guarani-kaiowá, Ava Yvy Vera (2016), em que os termos “tekoha” e "teko" definem uma especial forma de comunhão entre território e modo de vida (BRASIL, 2020, p.113). 